\title{
Weight neutrality with the DPP-4 inhibitor, vildagliptin: Mechanistic basis and clinical experience
}

This article was published in the following Dove Press journal:

Vascular Health and Risk Management

30 June 2010

Number of times this article has been viewed

\section{James E Foley' \\ Jens Jordan ${ }^{2}$}

'Clinical Research and Development, Novartis Pharmaceutical Corporation, East Hanover, New Jersey, USA; ${ }^{2}$ Institute for Clinical Pharmacology, Hannover Medical School, Hannover, Germany
Correspondence: James E Foley Novartis Pharmaceutical Corporation, Clinical Research and Development, One Health Plaza, East Hanover, NJ 07936, USA

Tel + I 8627783258

Fax + I 9737818496

Email james.foley@novartis.com
Abstract: Various factors may confound how diabetes medications affect a patient's weight. Agents that induce hypoglycemia may promote weight gain through "defensive eating". Conversely, patients whose hyperglycemia exceeds the renal glucose threshold may overeat to compensate for calories lost in urine and so gain weight when drug therapy ablates glycosuria. Some drugs, such as thiazolidinediones, may promote weight gain via increased lipid storage. Glucagon-like peptide-1 receptor agonists increase satiety, delay gastric emptying, and generally produce weight loss. Dipeptidyl peptidase (DPP)-4 inhibitors are generally weight-neutral, although modest weight loss has been observed with the DPP-4 inhibitor, vildagliptin, in patients with relatively low baseline glycemia. The weight neutrality of vildagliptin likely results in part from its intrinsically low risk for hypoglycemia. Recent studies point to additional potential mechanisms. One study found that drug-naïve patients randomized to vildagliptin exhibited significantly lower chylomicron lipid and apolipoprotein levels than placebo patients, suggesting that vildagliptin may inhibit intestinal fat extraction. Another trial found that patients randomized to vildagliptin versus placebo experienced paradoxical postprandial increases in markers of fatty acid mobilization and oxidation, in conjunction with increased sympathetic stimulation. Elaboration of these and other pathways could further clarify the origins of the favorable weight profile of vildagriptin.

Keywords: DPP-4 inhibitor, type 2 diabetes mellitus, vildagliptin, weight

\section{Introduction}

Overweight and/or obesity contribute to the risk of developing type 2 diabetes, and confound glycemic control once the disease develops. ${ }^{1}$ Interventions aimed at weight loss are recommended for the estimated $80 \%-90 \%$ of patients with type 2 diabetes whose weight exceeds normal. ${ }^{2-4}$ In such patients, successful weight loss can improve glycemic control, as well as reduce concomitant cardiovascular risk factors, eg, hypertension and dyslipidemia. ${ }^{1}$ Clinicians therefore need to pay close attention to the effects of diabetes therapies on body weight and adiposity.

In general terms, the potential effects of various antidiabetic drug classes on weight balance are well recognized. Both insulin and insulin secretagogues (sulfonylureas and glinides) promote weight gain, especially in regimens designed to achieve intensive glycemic control. Thiazolidinediones (TZDs) are associated with weight gain, while metformin is generally associated with weight neutrality or weight loss. Incretin-based therapies, including glucagon-like peptide (GLP)-1 receptor agonists and dipeptidyl peptidase (DPP)-4 inhibitors, are associated with weight loss or weight neutrality. ${ }^{1}$ 
A more detailed appreciation of how diabetes medications may affect a patient's weight, and the implications of such interactions on key factors including insulin sensitivity, requires consideration of various confounding factors. These factors include compensatory mechanisms that come into play at glycemic extremes (calorie wasting in hyperglycemia and defensive eating at the cusp of hypoglycemia), as well as the effects of specific treatments on lipid metabolism. This article examines the role of these and other factors, with a special focus on the weight neutrality of the DPP-4 inhibitor vildagliptin.

\section{Body weight and glycemic control}

Obesity contributes to an individual's risk of type 2 diabetes, largely through its contribution to insulin resistance..$^{5}$ Large fat cells resist insulin-mediated lipolysis suppression, resulting in excess free fatty acid (FFA) release. FFAs further promote insulin resistance, particularly in skeletal muscle and in the liver. Muscle cells require more insulin than normal to clear excess glucose from the blood, while in the liver normal levels of insulin fail to suppress adequately the release of glucose into the bloodstream. ${ }^{4,6,7}$ To compensate for insulin resistance, pancreatic $\beta$-cells produce extra insulin, resulting in elevated blood insulin levels. Frank diabetes emerges when the $\beta$-cells ultimately fail to compensate fully for insulin resistance., ${ }^{4,5}$

Uncontrolled diabetes sufficiently severe to produce the classic symptoms of excessive thirst, hunger, and urination typically entails weight loss despite elevated calorie intake, as insulin-dependent tissues "starve in the midst of plenty" and the kidneys respond to severe hyperglycemia by excreting excess glucose in the urine. Even in the absence of symptomatic disease, the kidneys will excrete glucose, and thus waste calories, when blood glucose levels exceed the renal glucose threshold, typically around $180 \mathrm{mg} / \mathrm{dL}(10 \mathrm{mmol} / \mathrm{L}$, Figure 1$)$, although this value varies substantially in individuals. ${ }^{8,9} \mathrm{An}$ individual whose glycemic levels frequently exceed the renal threshold may engage in compensatory overeating to recover calories lost in urine. In such a patient, initiation or intensification of glycemic control with an agent that increases insulin availability or enhances insulin action can result in weight gain, because glucose that otherwise would have been excreted is now taken up by body tissues. Reduction of glycosuria via improvement in glycemic control could thus produce weight gain.

At the other end of the glycemic spectrum (see Figure 1), agents capable of triggering hypoglycemic episodes can also promote weight gain, especially as part of an intensified regimen aimed at achieving normal or near-normal glycemic levels. The phenomenon was initially demonstrated in patients with type 1 diabetes in the Diabetes Control and Complications Trial, where at five years, patients randomized to intensive insulin therapy gained a mean of $4.6 \mathrm{~kg}$ more than those receiving conventional therapy. ${ }^{10}$ Patients in the intensive insulin therapy group also experienced significantly

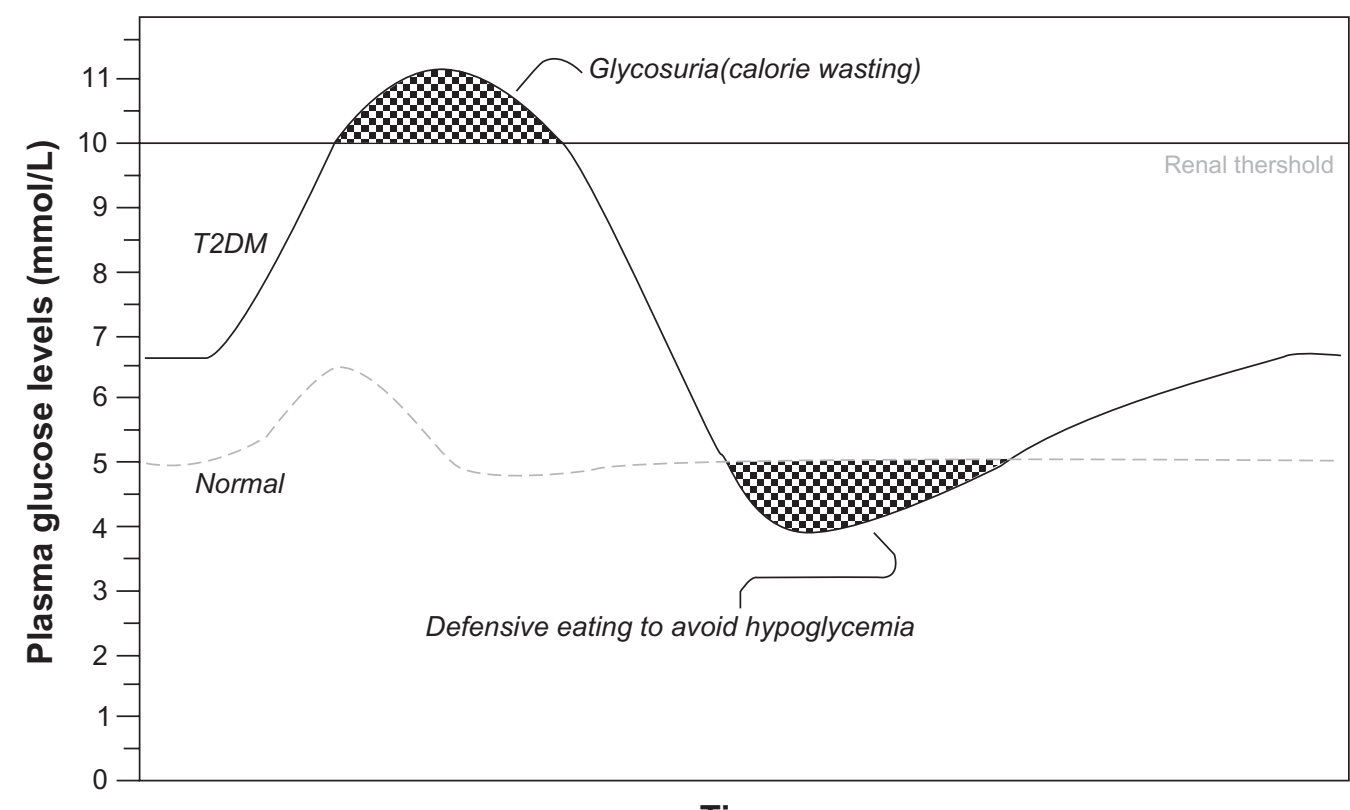

Time

Figure I Calorie wasting and defensive eating are possible results of fluctuating plasma glucose levels in type 2 diabetes, confounding weight management. Abbreviation: T2DM, type 2 diabetes. 
more, and more severe, hypoglycemic episodes. Patients with type 2 diabetes participating in the United Kingdom Prospective Diabetes Study were randomized to intensive sulfonylurea or insulin therapy or to less aggressive "conventional" therapy. Patients in the intensive therapy group experienced more hypoglycemic episodes and gained more weight, especially those taking insulin. ${ }^{11}$ The weight gain may be related in part to an increase in "defensive eating" to prevent a decline from normoglycemia to hypoglycemia.

\section{Agent- and class-specific effects}

Drug therapies can also influence weight balance by virtue of their effects on fat storage. Insulin potently inhibits lipolysis in adipocytes, thus promoting intracellular triglyceride storage. ${ }^{4}$ In a comparative study of insulin and sulfonylurea therapy in patients with type 2 diabetes, Birkeland et al demonstrated a significant body mass increase in insulintreated patients, of which only $30 \%$ was attributable to lean body mass. ${ }^{12}$

TZD package inserts also indicate that these drugs promote weight gain through increases in body fat mass, as well as through fluid retention. ${ }^{13,14}$ In a small placebocontrolled trial employing oral glucose tolerance tests and a two-step euglycemic insulin clamp technique, Miyazaki et al documented an increase in total body fat mass with rosiglitazone. ${ }^{15}$ The response correlated inversely with serum FFA levels and with FFA mobilization from adipocytes. The investigators suggested that the increased fat storage was partly attributable to enhanced adipocyte sensitivity to the antilipolytic action of endogenous insulin; additionally, they noted that rosiglitazone favors fat storage in peripheral rather than in the more lipolytically active visceral fat tissue, an observation corroborated for pioglitazone as well. ${ }^{16}$ The literature provides little concrete support for any significant contribution of fluid retention to the average additional weight gain seen with TZDs. Fewer than $10 \%$ of patients taking TZDs have peripheral edema. ${ }^{17}$ For instance, even if one-third of a $3 \mathrm{~kg}$ average TZD weight gain were due to edema, then those patients with peripheral edema (assuming $10 \%$ of them had edema) would need to have an average of at least $10 \mathrm{~kg}$ in fluid retention. Fluid retention contributes to noticeable weight gain in some patients, but in our view most TZD-associated weight gain comes from an increase in fat mass.

Two classes of type 2 diabetes agents, the GLP-1 receptor agonists and the DPP-4 inhibitors, reduce hyperglycemia by mimicking or enhancing incretin actions. Incretins are hormones released from the gut in response to food intake that increase the glucose sensitivity of pancreatic $\beta$ - and $\alpha$-cells. ${ }^{18}$ The two principal incretins, GLP-1 and glucose-dependent insulinotropic polypeptide (GIP), are responsible for the amplification of insulin secretion that occurs following an oral, as opposed to an equivalent intravenous, glucose load, ie, the incretin effect. Incretin-based pharmacotherapy improves glycemic control in patients with type 2 diabetes, in whom the incretin response is commonly impaired. ${ }^{19,20}$

Incretin hormones boost insulin secretion by $\beta$-cells only in the setting of rising glucose, ie, in a glucose-dependent manner. ${ }^{20}$ Early studies of the potential of incretin-based therapy, involving direct infusions of GLP-1 into both normal and type 2 diabetic individuals, confirmed such a self-limiting glucose-lowering effect. ${ }^{21,22}$ As a result, unlike indiscriminate insulin secretagogues, such as sulfonylureas and glinides, incretin-based therapies are associated with a rather low hypoglycemia risk and are therefore less likely to promote weight gain related to defensive eating.

The twice-daily injectable GLP-1 mimetic, exenatide, exhibits minimal risk of hypoglycemia when given as monotherapy. ${ }^{20,23}$ Early GLP-1 infusion studies also showed that at high doses the hormone increases subjective satiety and delays gastric emptying. ${ }^{24}$ These characteristics are also seen with exenatide and liraglutide therapies, which have been consistently demonstrated to produce weight loss in type 2 diabetic patients. ${ }^{23,25}$ In the six Phase III studies of the Liraglutide Effect and Action in Diabetes (LEAD) program, weight loss was observed with liraglutide treatment across all studies, and in LEAD-6, which directly compared liraglutide and exenatide, weight loss was shown to be comparable for both agents over 26 weeks ( $-3.2 \mathrm{~kg}$ for liraglutide, $-2.9 \mathrm{~kg}$ for exenatide). ${ }^{26,27}$

DPP-4 inhibitors bind and inhibit the enzyme that cleaves and inactivates GLP-1 and GIP. Inhibiting the degradation of these short-lived hormones increases their concentration and prolongs their activity. In contrast with GLP-1 receptor agonists, DPP-4 inhibitors enhance the action of endogenous incretins physiologically, at the time of their secretion. ${ }^{18}$

\section{Vildagliptin}

The extensively studied DPP-4 inhibitor, vildagliptin, enhances $\beta$ - and $\alpha$-cell sensitivity to glucose, resulting in an enhanced postprandial insulin response and blunted glucagon secretion, as well as improved fasting glycemia. ${ }^{18,28,29}$ Vildagliptin's mechanism of action appears to be associated with a low hypoglycemia risk in a wide range of settings and regimens, ${ }^{30-39}$ and presumably with a low risk for hypoglycemia-related defensive eating. 
Unlike exenatide, vildagliptin does not mimic infused GLP-1 with respect to subjective satiety or gastric volume, ${ }^{40}$ effects which have been associated with noticeable weight loss. Overall weight neutrality has been seen with vildagliptin, 1,31,32,34,37-39,41 as opposed to the weight gain seen with insulin and sulfonylureas. ${ }^{1,11}$

The overall weight neutrality seen with vildagliptin appears to be a class effect because the DPP-4 inhibitors, saxagliptin and sitagliptin, have also been shown to produce improvements in glycemic control, both as monotherapy and as add-on therapy to other oral agents, without significant change in body weight in most clinical trials. ${ }^{42-50}$

In a head-to-head randomized clinical trial in patients with relatively low baseline glycemic values (mean $\mathrm{HbA}_{1 \mathrm{C}} 7.3 \%$, fasting plasma glucose [FPG] $9.2 \mathrm{mmol} / \mathrm{L}$ [165 mg/dL]), patients inadequately controlled on metformin who were randomized to vildagliptin $50 \mathrm{mg}$ bid were weight stable at 52 weeks $(-0.2 \mathrm{~kg})$, which was highly significant compared with the weight gain seen in the comparator group receiving glimepiride $\leq 6 \mathrm{mg}$ daily (between-group difference $-1.8 \mathrm{~kg}$, $P<0.001){ }^{41}$ This difference presumably stems in part from the glucose-dependent "fail-safe" system that prevents even elevated incretin levels from overstimulating insulin secretion in the absence of elevated or rising glucose levels. Perhaps more important, whereas vildagliptin improves the sensitivity of the $\alpha$-cell to glucose, the sulfonylurea reduces it, leading to a more robust glucagon counterregulatory response with vildagliptin..$^{51}$

Additionally, the severity of baseline hyperglycemia, and the degree to which it may be accompanied by glycosuria, likely modulates the subsequent influence of vildagliptin on weight in clinical trials. Thus, baseline glycemic levels that frequently or chronically exceed the renal glucose threshold can confound weight balance in patients with diabetes. Mean baseline $\mathrm{HbA}_{1 \mathrm{C}}$ levels in the majority of vildagliptin monotherapy and add-on trials usually exceeded $8 \%$, corresponding to an estimated average glucose of $183 \mathrm{mg} / \mathrm{dL} .{ }^{52}$ Baseline fasting plasma glucose levels also tended to meet or exceed the typical renal threshold. Vildagliptin treatment was weight neutral or associated with only small increases in weight across these clinical trials. In one placebo-controlled trial of vildagliptin monotherapy in drug-naïve patients, for example, weight loss relative to baseline was seen in both active treatment and placebo groups. ${ }^{32}$ A slight gain in weight with vildagliptin monotherapy relative to placebo was observed in another study, although both vildagliptin and placebo groups showed a reduction relative to baseline. ${ }^{31}$ In head-to-head comparisons with rosiglitazone or metformin in drug-naïve patients, vildagliptin monotherapy achieved comparable levels of glycemic efficacy, with no changes in weight by the end of the studies. In contrast, patients receiving rosiglitazone experienced statistically significant weight gain, while patients receiving metformin lost weight. ${ }^{38,39}$

Reversal of renal caloric wasting as glycemic control improved may have offset some of the favorable weight effects that otherwise might have been seen with vildagliptin in these trials, potentially explaining the difference between the weight neutrality and actual weight loss. Consistent with this possibility, in a two-year randomized trial of vildagliptin monotherapy in patients with mild baseline hyperglycemia $\left(\mathrm{HbA}_{1 \mathrm{C}} 6.6 \%\right.$, FPG $\left.6.9 \mathrm{mmol} / \mathrm{L}[124 \mathrm{mg} / \mathrm{dL}]\right)$, patients randomized to vildagliptin achieved a mean $1.1 \mathrm{~kg}$ weight loss, which was statistically significant $(P=0.026)$ versus baseline. $^{34}$

\section{Potential novel mechanisms for weight neutrality}

Several recently identified mechanisms may explain the weight neutrality, and in some cases weight loss, associated with vildagliptin. In a single-center, randomized trial, drugnaïve type 2 diabetic patients randomized to vildagliptin (50 mg bid) or placebo underwent a fat tolerance test at baseline and at the conclusion of a four-week follow-up period. The fat tolerance test entailed consumption of a standardized fat-rich meal followed by assessment of multiple lipid, lipoprotein, and apolipoprotein parameters. ${ }^{53}$

Despite the short follow-up period and the relatively low mean $\mathrm{HbA}_{1 \mathrm{C}}$ levels ( $\sim 6.9 \%$ ) at baseline, the researchers documented statistically significant reductions in $\mathrm{HbA}_{1 \mathrm{C}}, \mathrm{FPG}$, and postprandial glucose with vildagliptin. In the fat tolerance test, vildagliptin reduced postchallenge circulating triglyceride levels compared with placebo. The response appeared to be related to corresponding statistically significant reductions in chylomicron triglyceride, chylomicron cholesterol, and chylomicron apolipoprotein (apo) B-48 levels. Reductions in the constituent lipid and apolipoprotein components of other triglyceride-rich lipoproteins (very low-density lipoprotein, intermediate-density lipoprotein) did not achieve statistical significance. ${ }^{53}$

Since chylomicrons are the initial lipoproteins into which dietary triglycerides are packaged, these findings suggest that vildagliptin may have an inhibitory effect on fat absorption from the gut (Figure 2). This notion is consistent with findings in rodents, in which exogenous GLP-1 inhibited intestinal triglyceride absorption and GIP infusion promoted chylomicron triglyceride clearance. The possibility that vilda- 


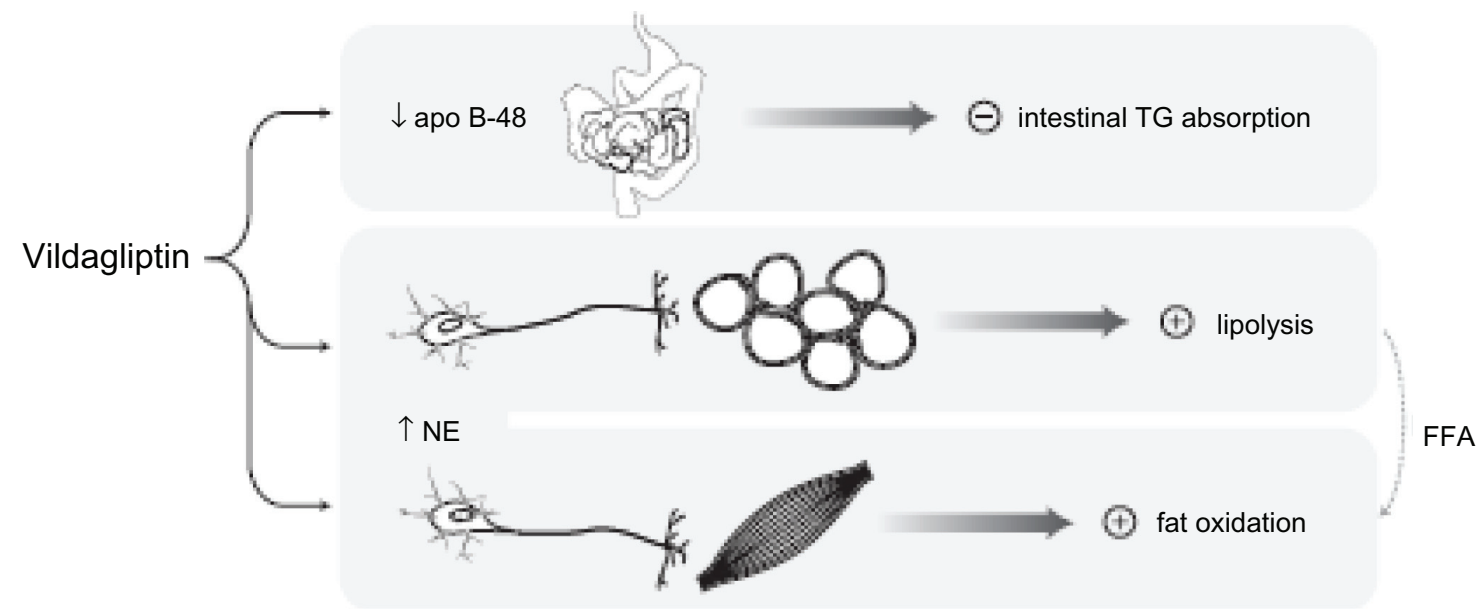

Figure 2 Mechanisms that may mitigate weight gain with vildagliptin during meals. Following a high-fat meal, vildagliptin was found to reduce levels of chylomicron apo B-48, suggesting that it may inhibit chylomicron-mediated triglyceride absorption from the gut. ${ }^{53}$ Vildagliptin was also associated with increased postprandial catecholamine levels, as well as markers of lipolysis in adipose tissue and fatty acid oxidation in skeletal muscle, suggestive of sympathetically mediated lipid mobilization and catabolism in the postabsorptive state. ${ }^{54}$

Abbreviations: FFA, free fatty acids; NE, norepinephrine; TG, triglyceride.

gliptin inhibits fat extraction from the gut, albeit to a lesser degree than a lipase inhibitor such as orlistat, constitutes a provocative pathway by which it may express its favorable weight profile. ${ }^{53}$

In another study of the effects of vildagliptin on postprandial metabolic parameters, Boschmann et al conducted a randomized, double-blind, crossover study in 20 patients with type 2 diabetes randomized to vildagliptin (100 $\mathrm{mg}$ daily) or placebo. On day 7, following an overnight fast, subjects were fitted with venous catheters and microdialysis probes in subcutaneous adipose tissue and skeletal muscle. Then, following a standardized meal, multiple lipid, endocrine, neuroendocrine, and metabolite factors were sampled at frequent intervals over the course of four hours. ${ }^{54}$

Vildagliptin augmented postprandial venous norepinephrine concentrations. At the same time, vildagliptin increased postprandial lactate and glycerol concentrations in adipose tissue and decreased lactate and pyruvate levels in skeletal muscle. These findings indicate that, contrary to the anabolic effects one might expect in response to incretin-enhanced postprandial insulin secretion, vildagliptin actually promotes lipolysis in adipose tissue in the postprandial state, in conjunction with increased fatty acid oxidation in skeletal muscle. The investigators postulate that the principal impetus for these effects comes not from endocrine pathways but from sympathetic stimulation, as suggested by the elevated norepinephrine levels. This evidence for mobilization and expenditure of stored fat calories concomitant with dietary calorie influx provides another intriguing pathway by which vildagliptin may promote favorable weight balance. ${ }^{54}$ Figure 2 provides an integrated depiction of the two pathways just described.

The limited mechanistic studies with other DPP-4 inhibitors preclude a generalization of mechanistic findings for vildagliptin to the class of DPP-4 inhibitors as a whole. For instance, it is not clear that the once-daily dosing with saxagliptin has the same effect on GLP-1 levels as seen with vildagliptin $50 \mathrm{mg}$ bid, and it is known that the increased GLP-1 levels observed at the onset of meals are maintained for much longer periods of time with vildagliptin than sitagliptin. ${ }^{55}$

\section{Weight and insulin resistance}

Clinical trial data and practical experience support a broad general consensus on the potential weight effects of various type 2 diabetes drug classes and individual agents. ${ }^{1,2,19}$ However, various confounding variables can influence these effects in different study cohorts or in individual patients. Moreover, whether a given regimen supports a "desirable" steady-state weight, achieves weight neutrality, or even promotes significant weight loss does not in itself reliably reflect the status of certain underlying disease processes, eg, insulin resistance and $\beta$-cell dysfunction.

For example, in multiple clinical trials ranging from 24 to 52 weeks of follow-up, exenatide was associated with significant weight loss as monotherapy, ${ }^{56}$ or when added to metformin, ${ }^{57,58}$ sulfonylurea, ${ }^{59}$ or metformin-sulfonylurea combination therapy. ${ }^{60}$ In all of these trials, mean BMI at 
baseline was greater than 30, ie, the National Heart Lung and Blood Institute's cutoff point for "obese". Although the ability of weight loss to ameliorate insulin resistance is well recognized, ${ }^{1}$ the one study that assessed insulin sensitivity (by hyperglycemic clamp) in a setting of exenatide-associated weight loss found that insulin sensitivity improved to the same degree in both exenatide- and insulin glargine-treated patients. ${ }^{57}$ The exenatide group experienced a mean weight reduction at one year of $3.6 \mathrm{~kg}$, while the glargine-treated group gained $1 \mathrm{~kg}$. The statistically significant betweengroup disparity in weight control did not, as one might have expected, generate greater improvement in insulin sensitivity in the exenatide group. ${ }^{57}$

By contrast, despite more modest weight benefits in contrast with exenatide, vildagliptin treatment has been found to improve insulin sensitivity as monotherapy or as an add-on to metformin in a series of studies in which insulin sensitivity was assessed by insulin clamp, ${ }^{61}$ the oral glucose insulin sensitivity model, ${ }^{62}$ or frequently sampled intravenous glucose tolerance testing. ${ }^{63,64}$ In the clamp-assessed study, insulin sensitivity improved by about $15 \%$ after six weeks of vildagliptin therapy in a combined cohort of drug-naïve and metformin-treated type 2 diabetic patients. ${ }^{61}$

The reasons for these discrepancies between weight effects and insulin sensitivity are unclear. They may reflect the dynamics of caloric balance in the patients treated with exenatide or vildagliptin, ie, the patients who lost weight in the exenatide trials may have initially lost weight and then had a sustained period of a very small degree of positive caloric balance, whereas those taking vildagliptin might have persisted, to a very small degree, in an ongoing state of negative calorie balance despite minimal net weight change.

The improved insulin sensitivity seen after six weeks of vildagliptin therapy, as assessed by the euglycemic-hyperinsulinemic clamp described above, was also associated with decreased fasting lipolysis and decreased fat oxidation, ${ }^{61}$ which is consistent with reduced stored triglyceride in nonfat tissues. This finding supports the therapeutic potential of vildagliptin for ameliorating nonalcoholic fatty liver disease. $^{65}$

\section{Conclusions}

Vildagliptin is a potent and specific DPP-4 inhibitor that has demonstrated weight neutrality in patients with type 2 diabetes in multiple monotherapy and combination trials. The low risk of hypoglycemia with vildagliptin, stemming from its glucose-dependent mechanism of action, likely contributes to this weight neutrality by obviating the "defensive eating" that can occur with exogenous insulin or glucose-independent insulin secretagogues. However, additional evidence suggests that vildagliptin may influence postprandial lipid and lipoprotein metabolism by inhibiting triglyceride absorption from the gut ${ }^{53}$ and/or promoting sympathetically mediated lipid mobilization and catabolism in the postabsorptive state. ${ }^{54}$ Further elaboration of these pathways could provide a mechanistic basis for understanding the favorable effects on weight associated with vildagliptin therapy. In addition, insulin has centrally mediated actions on hunger that could be attenuated by the more glucose-sensitive insulin profile of vildagliptin, and these have yet to be evaluated.

\section{Acknowledgment}

We thank Joe Hirsch, from BioScience Communications, who provided medical writing support funded by Novartis.

\section{Disclosure}

James E Foley is an employee of Novartis. Jens Jordan has served as scientific advisor for and received research support from Abbott, Novartis, and Sanofi-Aventis.

\section{References}

1. Nathan DM, Buse JB, Davidson MB, et al. Medical management of hyperglycemia in type 2 diabetes: A consensus algorithm for the initiation and adjustment of therapy: A consensus statement of the American Diabetes Association and the European Association for the Study of Diabetes. Diabetes Care. 2009;32:193-203.

2. Rodbard HW, Jellinger PS, Davidson JA, et al. Statement by an American Association of Clinical Endocrinologists/American College of Endocrinology consensus panel on type 2 diabetes mellitus: An algorithm for glycemic control. Endocrine Practice. 2009;15:540-559.

3. American Diabetes Association. Standards of medical care in diabetes - 2010. Diabetes Care. 2010;33 Suppl 1:S11-S61.

4. DeFronzo RA. Pathogenesis of type 2 diabetes mellitus. Med Clin NAm. 2004;88:787-835.

5. American Diabetes Association. Diagnosis and classification of diabetes mellitus. Diabetes Care. 2010;33 Suppl 1:S62-S69.

6. Paolisso G, Tataranni PA, Foley JE, Bogardus C, Howard BV, Ravussin E. A high concentration of plasma free fatty acids is a risk factor for the development of non-insulin-dependent diabetes mellitus. Diabetologia. 1995;38:1213-1217.

7. Weyer C, Foley JE, Bogardus C, Tataranni PA, Pratley RE. Enlarged subcutaneous abdominal adipocyte size, but not obesity itself, predicts type II diabetes independent of insulin resistance. Diabetologia. 2000;43:1498-1506.

8. Rave K, Nosek L, Posner J, Heise T, Roggen K, van Hoogdalem EJ. Renal glucose excretion as a function of blood glucose concentration in subjects with type 2 diabetes: results of a hyperglycaemic glucose clamp study. Nephrol Dial Transplant. 2006;21:2166-2171.

9. IDF.org. Brussels: International Diabetes Federation. Position Statement - Urine Glucose Monitoring. 2005 Mar. Available from: http://www.idf.org/Position_statementsurine_monitoring. Accessed Dec 16, 2009.

10. The Diabetes Control and Complications Trial Research Group. The effect of intensive treatment of diabetes on the development and progression of long-term complications in insulin-dependent diabetes mellitus. N Engl J Med. 1993;329:977-986. 
11. UK Prospective Diabetes Study (UKPDS) Group. Intensive blood-glucose control with sulphonylureas or insulin compared with conventional treatment and risk of complications in patients with type 2 diabetes (UKPDS 33). Lancet. 1998;352:837-853.

12. Birkeland KI, Hanssen KF, Urdal P, Berg K, Vaaler S. A long-term, randomized, comparative study of insulin versus sulfonylurea therapy in type 2 diabetes. $J$ Intern Med. 1994;236:305-313.

13. Actos [Package insert]. Deerfield, IL: Takeda Pharmaceuticals America, Inc.; 2009.

14. Avandia [Package insert]. Research Triangle Park, NC: GlaxoSmithKline; 2008

15. Miyazaki Y, Glass L, Triplitt C, et al. Effect of rosiglitazone on glucose and non-esterified fatty acid metabolism in type II diabetic patients. Diabetologia. 2001;44:2210-2219.

16. Boden $\mathrm{G}$, Zhang $\mathrm{M}$. Recent findings concerning thiazolidinediones in the treatment of diabetes. Expert Opin Investig Drugs. 2006;15:243-250.

17. Nesto RW, Bell D, Bonow RO, et al. Thiazolidinedione use, fluid retention, and congestive heart failure. Diabetes Care. 2004;27:256-263.

18. Ahrén B, Foley JE. The islet enhancer vildagliptin: Mechanisms of improved glucose metabolism. Int J Clin Pract. 2008;62 Suppl 159: $8-14$.

19. NICE.org.uk. London: National Institute for Health and Clinical Excellence (NICE). Type 2 diabetes: Newer agents for blood glucose in type 2 diabetes. 2009 May. Available from: www.nice.org.uk/CG87ShortGuideline Accessed Dec 16, 2009.

20. Nauck MA, Meier JJ. Glucagon-like peptide 1 and its derivatives in the treatment of diabetes. Regulatory Peptides. 2005;128:135-148.

21. Holst JJ, Toft-Nielsen MB, Orskov C, Nauck M, Willms B. On the effects of glucagon-like peptide-1 on blood glucose regulation in normal and diabetic subjects. Ann N Y Acad Sci. 1996;805:729-736.

22. Toft-Nielsen M, Madsbad S, Holst J. Determinants of the effectiveness of glucagon-like peptide-1 in type 2 diabetes. J Clin Endocrinol Metab. 2001;86:3853-3860

23. Byetta [Package insert]. San Diego, CA: Amylin Pharmaceuticals, Inc.; 2009.

24. Flint A, Raben A, Astrup A, Holst JJ. Glucagon-like peptide 1 promotes satiety and suppresses energy intake in humans. J Clin Invest. 1998; 101:515-520.

25. Victoza [Package insert]. Bagsvaerd, Denmark: Novo Nordisk A/S; 2010.

26. Blonde L, Russell-Jones D. The safety and efficacy of liraglutide with or without oral antidiabetic drug therapy in type 2 diabetes: An overview of the LEAD 1-5 studies. Diabetes Obes Metab. 2009;11 Suppl 3:26-34.

27. Buse JB, Rosenstock J, Sesti G, et al; LEAD-6 Study Group. Liraglutide once a day versus exenatide twice a day for type 2 diabetes: A 26-week randomised, parallel-group, multinational, open-label trial (LEAD-6). Lancet. 2009;374:39-47.

28. Ahrén B, Landin-Olsson M, Jansson PA, Svensson M, Holmes D, Schweizer A. Inhibition of dipeptidyl peptidase-4 reduces glycemia, sustains insulin levels, and reduces glucagon levels in type 2 diabetes. J Clin Endocrinol Metab. 2004;89:2078-2084.

29. Mari A, Sallas WM, He YL, et al. Vildagliptin, a dipeptidyl peptidase-IV inhibitor, improves model-assessed beta-cell function in patients with type 2 diabetes. J Clin Endocrinol Metab. 2005;90:4888-4894.

30. Galvus [Package insert]. West Sussex, UK: Novartis Europharm; 2008.

31. Pi-Sunyer FX, Schweizer A, Mills D, Dejager S. Efficacy and tolerability of vildagliptin monotherapy in drug-naïve patients with type 2 diabetes. Diabetes Res Clin Pract. 2007;76:132-138.

32. Dejager S, Razac S, Foley JE, Schweizer A. Vildagliptin in drug-naïve patients with type 2 diabetes: A 24-week, double-blind, randomized, placebo-controlled, multiple-dose study. Horm Metab Res. 2007;39:218-223.

33. Scherbaum WA, Schweizer A, Mari A, et al. Efficacy and tolerability of vildagliptin in drug-naïve patients with type 2 diabetes and mild hyperglycaemia. Diabetes Obes Metab. 2008;10:675-682.
34. Scherbaum WA, Schweizer A, Mari A, et al. Evidence that vildagliptin attenuates deterioration of glycaemic control during 2-year treatment of patients with type 2 diabetes and mild hyperglycaemia. Diabetes Obes Metab. 2008;10:1114-1124.

35. Fonseca V, Schweizer A, Albrecht D, Baron MA, Chang I, Dejager S. Addition of vildagliptin to insulin improves glycaemic control in type 2 diabetes. Diabetologia. 2007;50:1148-1155.

36. Fonseca V, Baron M, Shao Q, Dejager S. Sustained efficacy and reduced hypoglycemia during one year of treatment with vildagliptin added to insulin in patients with type 2 diabetes mellitus. Horm Metab Res. 2008; $40: 427-430$

37. Garber AJ, Foley JE, Banerji MA, et al. Effects of vildagliptin on glucose control in patients with type 2 diabetes inadequately controlled with a sulphonylurea. Diabetes Obes Metab. 2008;10:1047-1056.

38. Schweizer A, Couturier A, Foley JE, Dejager S. Comparison between vildagliptin and metformin to sustain reductions in $\mathrm{HbA}_{1 \mathrm{c}}$ over 1 year in drug-naïve patients with type 2 diabetes. Diabet Med. 2007;24:955-961.

39. Rosenstock J, Baron MA, Dejager S, Mills D, Schweizer A. Comparison of vildagliptin and rosiglitazone monotherapy in patients with type 2 diabetes: A 24-week, double-blind, randomized trial. Diabetes Care. 2007;30:217-223.

40. Vella A, Bock G, Giesler PD, et al. The effect of dipeptidyl peptidase-4 inhibition on gastric volume, satiation and enteroendocrine secretion in type 2 diabetes: A double-blind, placebo-controlled crossover study. Clin Endocrinol (Oxf). 2008;69:737-744.

41. Ferrannini E, Fonseca V, Zinman B, et al. Fifty-two-week efficacy and safety of vildagliptin vs glimepiride in patients with type 2 diabetes mellitus inadequately controlled on metformin monotherapy. Diabetes Obes Metab. 2009;11:157-166.

42. Rosenstock J, Sankoh S, List JF. Glucose-lowering activity of the dipeptidyl peptidase-4 inhibitor saxagliptin in drug-naive patients with type 2 diabetes. Diabetes Obes Metab. 2008;10:376-386.

43. Rosenstock J, Aguilar-Salinas C, Klein E, Nepal S, List J, Chen R; CV181-011 Study Investigators. Effect of saxagliptin monotherapy in treatment-naïve patients with type 2 diabetes. Curr Med Res Opin. 2009;25:2401-2411.

44. DeFronzo RA, Hissa MN, Garber AJ, et al; Saxagliptin 014 Study Group. The efficacy and safety of saxagliptin when added to metformin therapy in patients with inadequately controlled type 2 diabetes with metformin alone. Diabetes Care. 2009;32:1649-1655.

45. Hollander P, Li J, Allen E, Chen R; CV181-013 Investigators. Saxagliptin added to a thiazolidinedione improves glycemic control in patients with type 2 diabetes and inadequate control on thiazolidinedione alone. $J$ Clin Endocrinol Metab. 2009;94:4810-4819.

46. Aschner P, Kipnes MS, Lunceford JK, Sanchez M, Mickel C, Williams-Herman DE; Sitagliptin Study 021 Group. Effect of the dipeptidyl peptidase-4 inhibitor sitagliptin as monotherapy on glycemic control in patients with type 2 diabetes. Diabetes Care. 2006;29: 2632-2637.

47. Charbonnel B, Karasik A, Liu J, Wu M, Meininger G; Sitagliptin Study 020 Group. Efficacy and safety of the dipeptidyl peptidase-4 inhibitor sitagliptin added to ongoing metformin therapy in patients with type 2 diabetes inadequately controlled with metformin alone. Diabetes Care. 2006;29:2638-2643.

48. Rosenstock J, Brazg R, Andryuk PJ, Lu K, Stein P; Sitagliptin Study 019 Group. Efficacy and safety of the dipeptidyl peptidase-4 inhibitor sitagliptin added to ongoing pioglitazone therapy in patients with type 2 diabetes: A 24 -week, multicenter, randomized, double-blind, placebo-controlled, parallel-group study. Clin Ther. 2006;28:1556-1568.

49. Nauck MA, Meininger G, Sheng D, Terranella L, Stein PP; Sitagliptin Study 024 Group. Efficacy and safety of the dipeptidyl peptidase-4 inhibitor, sitagliptin, compared with the sulfonylurea, glipizide, in patients with type 2 diabetes inadequately controlled on metformin alone: A randomized, double-blind, non-inferiority trial. Diabetes Obes Metab. 2007;9:194-205. 
50. Raz I, Hanefeld M, Xu L, Caria C, Williams-Herman D, Khatami H; Sitagliptin Study 023 Group. Efficacy and safety of the dipeptidyl peptidase-4 inhibitor sitagliptin as monotherapy in patients with type 2 diabetes mellitus. Diabetologia. 2006;49:2564-2571.

51. Ahrén B, Foley JE, Ferrannini E, et al. Changes in prandial glucagon levels after 2-year treatment with vildagliptin or glimepiride in patients with type 2 diabetes mellitus inadequately controlled with metformin therapy. Diabetes Care. 2010;33:730-732.

52. Nathan DM, Kuenen J, Borg R, et al. Translating the A1C assay into estimated average glucose values. Diabetes Care. 2008;31:1-6.

53. Matikainen N, Mänttäri S, Schweizer A, et al. Vildagliptin therapy reduces postprandial intestinal triglyceride-rich lipoprotein particles in patients with type 2 diabetes. Diabetologia. 2006;49:2049-2057.

54. Boschmann M, Engeli S, Dobberstein K, et al. Dipeptidyl-peptidase-IV inhibition augments postprandial lipid mobilization and oxidation in type 2 diabetic patients. J Clin Endocrinol Metab. 2009;94:846-852.

55. Marfella R, Barbieri M, Grella R, Rizzo MR, Nicoletti GF, Paolisso G. Effects of vildagliptin twice daily vs sitagliptin once daily on 24-hour acute glucose fluctuations. J Diabetes Complications. 2010; 24:79-83.

56. Moretto TJ, Milton DR, Ridge TD, et al. Efficacy and tolerability of exenatide monotherapy over 24 weeks in antidiabetic drug-naive patients with type 2 diabetes: A randomized, double-blind, placebo-controlled, parallel-group study. Clin Ther. 2008;30:1448-1460.

57. Bunck MC, Diamant M, Cornér A, et al. One-year treatment with exenatide improves beta-cell function, compared with insulin glargine, in metformin-treated type 2 diabetic patients: A randomized, controlled trial. Diabetes Care. 2009;32:762-768.

58. DeFronzo RA, Ratner RE, Han J, Kim DD, Fineman MS, Baron AD. Effects of exenatide (exendin-4) on glycemic control and weight over 30 weeks in metformin-treated patients with type 2 diabetes. Diabetes Care. 2005;28:1092-1100.
59. Buse JB, Henry RR, Han J, Kim DD, Fineman MS, Baron AD; Exenatide-113 Clinical Study Group. Effects of exenatide (exendin-4) on glycemic control over 30 weeks in sulfonylurea-treated patients with type 2 diabetes. Diabetes Care. 2004;27:2628-2635.

60. Kendall DM, Riddle MC, Rosenstock J, et al. Effects of exenatide (exendin-4) on glycemic control over 30 weeks in patients with type 2 diabetes treated with metformin and a sulfonylurea. Diabetes Care. 2005;28:1083-1091.

61. Radikova Z, Azuma K, Thomas E, et al. Effects of vildagliptin on postprandial glucose homeostasis in type 2 DM. Diabetologia. 2006;49 Suppl 1:401.

62. Ahrén B, Pacini G, Foley JE, Schweizer A. Improved meal-related beta-cell function and insulin sensitivity by the dipeptidyl peptidase-IV inhibitor vildagliptin in metformin-treated patients with type 2 diabetes over 1 year. Diabetes Care. 2005;28:1936-1940.

63. D'Alessio DA, Watson CE, He YL, et al. Restoration of acute insulin response to glucose (AIRg) in drug-naive patients with type 2 diabetes (T2 DM) by 3-month treatment with vildagliptin. Diabetes. 2006;55 Suppl 1:A108.

64. Utzschneider KM, Tong J, Montgomery B, et al. The dipeptidyl peptidase-4 inhibitor vildagliptin improves beta-cell function and insulin sensitivity in subjects with impaired fasting glucose. Diabetes Care. 2008;31:108-113.

65. Yilmaz Y, Atug O, Yonal O, et al. Dipeptidyl peptidase IV inhibitors: Therapeutic potential in nonalcoholic fatty liver disease. Med Sci Monit. 2009;15:HY1-HY5.
Vascular Health and Risk Management

\section{Publish your work in this journal}

Vascular Health and Risk Management is an international, peerreviewed journal of therapeutics and risk management, focusing on concise rapid reporting of clinical studies on the processes involved in the maintenance of vascular health; the monitoring, prevention and treatment of vascular disease and its sequelae; and the involvement of

\section{Dovepress}

metabolic disorders, particularly diabetes. This journal is indexed on PubMed Central and MedLine. The manuscript management system is completely online and includes a very quick and fair peer-review system, which is all easy to use. Visit http://www.dovepress.com/ testimonials.php to read real quotes from published authors. 